\title{
Peri-implant disease: early diagnosis and non-surgical treatment-a narrative literature review
}

\author{
TaeHyun Kwon ${ }^{1}$, Howard H. Yen ${ }^{1}$, Liran Levin ${ }^{2}$ \\ ${ }^{1}$ Private Practice, Keene, NH, USA; ${ }^{2}$ Division of Periodontology, Faculty of Medicine and Dentistry, University of Alberta, Edmonton, AB, Canada \\ Contributions: (I) Conception and design: T Kwon, L Levin; (II) Administrative support: T Kwon, L Levin; (III) Provision of study materials \\ or patients: T Kwon, HH Yen; (IV) Collection and assembly of data: T Kwon, HH Yen; (V) Data analysis and interpretation: All authors; (VI) \\ Manuscript writing: All authors; (VII) Final approval of manuscript: All authors. \\ Correspondence to: TaeHyun Kwon, DDS, MMSc. Monadnock Perio \& Implant Center, 819 Court street, Unit A, Keene, NH 03431, USA. \\ Email: tkwon3@gmail.com.
}

Objective: The purpose of this narrative review is to help clinicians understand the main etiologic factor, commonly identified contributing factors, early diagnostic science, and non-surgical therapeutic modalities of peri-implant diseases.

Background: Peri-implant diseases (i.e., peri-implant mucositis and peri-implantitis) are common biological complications of dental implant therapy, which may result in the failure of dental implants. Understanding the etiologic and contributing factors is the key to identify implants that are potentially at risk for peri-implant diseases. Furthermore, early diagnosis allows clinicians to execute initial non-surgical therapy in a timely manner, thus, potentially avoiding premature implant failure.

Methods: Literature search was conducted using specific keywords related to diagnosis and non-surgical management of peri-implant diseases. Relevant literature between January 1st, 1993 and April 30th, 2021 were carefully selected and included in this narrative review.

Conclusions: Patients with potential contributing factors for peri-implant diseases should be monitored carefully for early signs of peri-implant diseases. These factors include smoking habit, active or past history of periodontal diseases, unfavorable restorative conditions (i.e., excessive cements, excessive occlusion, limited access for plaque removal), lack of regular maintenance therapy, diabetes, and lack of keratinized tissue. Bleeding on probing appeared to be the most reliable early sign of peri-implant diseases. Initial non-surgical treatment should be delivered based on the principles of cause related therapy, specifically targeting the major etiologic factor for peri-implant diseases, dental plaque. During this phase, in addition to professional mechanical debridement, patient's active participation in removing dental plaque through home oral care is indispensible to achieve successful outcome. Any contributing factor should be eliminated or minimized. In cases with advanced peri-implantitis, a surgical therapy is often necessary. After successfully resolving peri-implant diseases, a regular maintenance therapy should be provided which allows continuous monitoring of patients and their implants.

Keywords: Peri-implantitis; peri-implant mucositis; implant failure; implant complication; dental implant; alveolar bone

Received: 28 April 2021; Accepted: 27 August 2021; Published: 30 December 2022.

doi: $10.21037 /$ fomm-21-58

View this article at: https://dx.doi.org/10.21037/fomm-21-58 


\section{Introduction}

Peri-implant diseases are common biological complications of dental implant therapy, which may result in the failure of dental implants (1). Clinicians should understand the etiology and contributing factors of these common diseases. This allows for early identification, diagnosis, and initial non-surgical treatments for at-risk implants in a timely manner. The purpose of this narrative review is to help clinicians understand the main etiologic factor, commonly identified contributing factors, early diagnostic science, and non-surgical therapeutic modalities of peri-implant diseases.

Peri-implant mucositis refers to an inflammation that is confined in soft tissue attachment around dental implant fixture (2). An implant with peri-implant mucositis often accompanies erythema and edema around peri-implant marginal mucosa in addition to bleeding on gentle probing (2). Similar to plaque-induced gingivitis, peri-implant mucositis is reversible with appropriate treatment (3). In comparison, peri-implantitis refers to an inflammation in supporting alveolar bone as well as softtissue attachment, which results in irreversible destruction of alveolar bone (3). Similar to periodontitis, the levels of pro-inflammatory cytokines such as interleukin-1 $\beta$ (IL-1 $\beta$ ) and matrix metalloproteinase-8 (MMP-8) were elevated in the crevicular fluid that were collected from the fixtures with peri-implantitis compared to healthy counterparts (4). In addition to the clinical signs of peri-implant mucositis, an implant with peri-implantitis may accompany suppuration, pain, and mobility. According to a recent meta-analysis (3), the prevalence of peri-implant mucositis is approximately $43 \%$ while that of peri-implantitis is $22 \%$. Similarly, another meta-analysis reported the prevalence of peri-implant mucositis and peri-implantitis of $30.7 \%$ and $9.6 \%$ respectively (5). The observed differences in their prevalence might be attributed to heterogeneous definitions of the diseases and variations in the study population. Peri-implant disease affects a significant number of dental implants and patients (6). Furthermore, peri-implant diseases, particularly, peri-implantitis progresses in a nonlinear and accelerating pattern, thus, making its early diagnosis critical (7). Peri-implant diseases are, in most cases, asymptomatic and not perceived by the patients, making their diagnosis challenging (8). Thus, clinicians should continuously monitor implants in function on a regular basis. To avoid implant loss, patients who were diagnosed with peri-implant diseases should also be treated without a delay (9). Thus, clinicians should understand the pathophysiology underlying peri-implant diseases, including diagnosis, etiology and contributing factors (6). The understanding of this newly emerging disease is a key factor in successfully devising a preventive regimen, recognizing early signs of the disease, and providing a conservative nonsurgical treatment in a timely manner $(1,6)$. We present the following article in accordance with the Narrative Review reporting checklist (available at https://fomm.amegroups. com/article/view/10.21037/fomm-21-58/rc) (10).

\section{Methods}

A search of PubMed was conducted using the following keywords: "Peri-Implantitis/classification"[Mesh] OR "Peri-Implantitis/complications"[Mesh] OR "Peri-Implantitis/diagnosis"[Mesh] OR "PeriImplantitis/epidemiology" [Mesh] OR "PeriImplantitis/etiology"[Mesh] OR "Peri-Implantitis/ physiopathology"[Mesh] OR "Peri-Implantitis/ surgery"[Mesh] OR "Peri-Implantitis/therapy"[Mesh] OR "Peri-implant mucositis. The inclusion criteria for selection were articles written in English, which were published between January 1st, 1993 to April, 30th, 2021 on periimplant diseases (peri-implant mucositis, peri-implantitis), their epidemiology, etiology, risk factors, diagnosis and nonsurgical treatment. Any studies not meeting the inclusion criteria were excluded. Articles were further selected by reviewing titles, abstracts and full texts by two reviewers (TK, HHY) based on their expertise in the subject. Any disagreement between the two reviewers in selecting articles was resolved by the third reviewer (LL) until a consensus was reached. The search was further augmented by manually searching reference lists from the articles that were included in this narrative review.

\section{Etiologic and contributing factors for peri- implant diseases}

\section{Dental plaque}

Dental plaque is the most important etiologic factor for peri-implant diseases (3). Dental plaque accumulation at dental implants triggers the inflammatory response leading to peri-implant mucositis and peri-implantitis (11). It is evident that periodontal diseases and peri-implant diseases are not functionally different from the perspectives of etiology and pathogenesis (12). The early stage of periimplant diseases was possibly associated with a shift in 
microbiome similar to those of periodontitis (13). It is the inflammation in response to microbial challenge that may eventually result in progressive alveolar bone destruction surrounding teeth or implants in periodontitis and periimplantitis respectively $(7,12,14)$. Evidence suggests that progressive crestal bone loss around dental implants in the absence of clinical signs of soft-tissue inflammation is a rare event (7). Considering that the presence of dental plaque in the sub-mucosal tissue surrounding the implants may initiate peri-implant diseases $(1,12)$, both preventive and active therapy for peri-implant diseases should be aimed at continuously removing dental plaque. Patients with poor oral hygiene were at 15 times greater risk of peri-implantitis compared to patients with good oral hygiene (15). Based on the principles of cause related therapy which has been successfully utilized in the treatment of periodontitis $(16,17)$, clinicians should educate their prospective implant patients about pathogenesis of peri-implant diseases, and the etiologic factor, dental plaque. Furthermore, clinicians should help their patients develop effective home oral care, prior to proceeding with actual dental implant therapy even for a patient who is planned to have full mouth extractions and implant therapy (18). Only after patients demonstrate their understanding of peri-implant diseases and the therapeutic nature of their home oral care in preventing peri-implant diseases, implant therapy should be initiated. $(1,18)$ During the restorative phase, clinicians should carefully design the prosthesis. The prosthesis should not promote plaque accumulation but rather allow patients to perform home care therapy without any difficulty. Following the completion of restorative therapy on implants, clinicians should also recommend a set of plaque removal devices that are specific to each patient based on, but not limited to, the type of restorations, embrasure size, and patient's manual dexterity (19).

\section{Smoking}

Patients with smoking habits who undergo implant therapy exhibit a greater risk for peri-implant diseases (3,20-22). According to Levin et al. (2011) (21), in an analysis of a total of 2,336 implants with follow-up time up to 144 months, smokers exhibited similar implant survival compared to non-smokers during the first 50 months. However, after 50 months, smokers appeared to have a 2.76 times greater risk of implant failure compared to non-smokers (21). Additionally, in a recent cohort study of a total of 710 implants, smokers (current or former) exhibited 6.35 times greater odds for implant failure compared to non-smokers (23). Similar to that of periodontitis, the elevated risk of peri-implantitis in smokers compared to non-smoker is possibly due to their potentially harboring periodontal pathogens and alteration in their host immune response (24-27). Prior to initiating dental implant therapy, clinicians should focus on smoking cessation to ensure long-term success of dental implant therapy. Furthermore, clinicians should clearly inform patients with smoking habit about potential risk of implant failure and continuously monitor their implants in longterm especially beyond their 50 months in function (21).

\section{Active or past bistory of periodontitis \& lack of regular maintenance therapy}

Patients with active or past history of periodontitis are at a greater risk for developing peri-implant diseases $(7,15,28)$. According to a recent systematic review with meta-analysis, individuals with past history of periodontitis or active periodontitis showed a 2.15 times greater risk of developing peri-implantitis compared to periodontally healthy individuals (29). In a long-term cohort study of patients with severe periodontitis who underwent implant therapy, compared to their periodontally healthy counterparts, patients with periodontitis exhibited an up to 14 times greater risk of developing peri-implantitis (30). In a recent retrospective study with 10 year follow-up, $83.3 \%$ of implant failure occurred in patients with recurrent periodontal disease while $16.7 \%$ implant failure occurred in patients without recurrent periodontal diseases (31). Furthermore, implants in patients with a residual periodontal pocket of $6 \mathrm{~mm}$ or more were at 5.47 greater risk of developing peri-implantitis than those with no residual periodontal pocket (32). The transmission of common periodontal pathogens from the adjacent natural dentition with periodontal pockets to implant sulcus was also reported, which in turn may result in the initiation of localized host pro-inflammatory response, and hence, peri-implant disease in a susceptible patient (33). A recent cross-sectional study reported a similar pro-inflammatory cytokine profile between gingival crevicular fluids collected from a periodontitis site and peri-implant crevicular fluids collected from a peri-implantitis site (34).

Regular implant maintenance therapy was also associated with a reduced incidence of peri-implant disease $(35,36)$. In a 5 -year follow-up study of investigating individuals with peri-implant mucositis, the incidence 

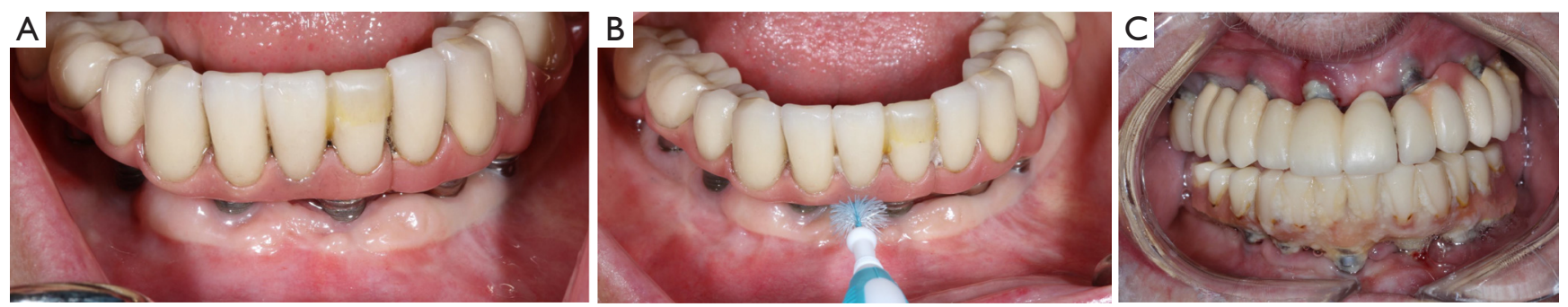

Figure 1 Restorative considerations to allow proper access for plaque removal around dental implant-prosthetic complex. (A) Although clinically there was evidence of peri-implant mucosal recession, which was associated with alveolar bone loss around dental implant fixtures, the patient had her implant supported fixed hybrid prosthesis for approximately 15 years. Clinically, there was minimally visible dental plaque around the implant fixtures, suggesting patient's effective plaque removal. (B) The existing restoration allows easy and passive insertion of a plaque removal device, in her case, interproximal dental brush. (C) The patient presented with maxillary and mandibular implant supported fixed hybrid prosthesis. Clinically, a heavy accumulation of dental plaque was noted around dental implants, suggesting ineffective oral hygiene care. As a result, active peri-implantitis was noted, possibly leading to implant failure in near future.

of peri-implantitis was $43.9 \%$ for a group without preventive maintenance therapy and $18.0 \%$ for a group with regular preventive maintenance therapy (35). In a systematic review with meta-analysis, patients with regular peri-implant maintenance therapy exhibited $10 \%$ increase in implant survival compared to patients without maintenance therapy over 1-10 year follow-up period (37). In addition, patients with regular maintenance therapy exhibited $43 \%$ and $75 \%$ reduction in the prevalence of peri-implant mucositis and peri-implantitis respectively over 4 year to 68.2 month follow-up period (37). Regular maintenance therapy included oral hygiene reinforcement and professional mechanical debridement (37). During the maintenance therapy, clinicians should perform a comprehensive periodontal and peri-implant mucosal examinations. Clinicians should understand and discuss with patients that implant therapy must not be limited to the placement and restoration of dental implants but to the implementation of peri-implant maintenance therapy to prevent biologic complications to ensure long-term survival of the implant (38).

\section{Restorative considerations}

Since dental plaque is an etiologic factor for periimplant diseases, restorations on dental implants should be carefully designed or modified so that they allow patients to remove dental plaque easily and effectively (3). In a recent cross-sectional study evaluating 171 implants, only $46 \%$ of the prostheses allowed proper access for performing interproximal plaque removal (39).
Clinicians should educate and help their patients develop competency in effectively using a specific oral device based on the embrasure space, patient's manual dexterity and patient's motivation level (Figure 1) (19). If possible, a screw-retained restoration should be considered over a cement-retained restoration to avoid extrusion of excessive cement material into peri-implant sulcus (40-43). Excessive cement residues in peri-implant sulcus was associated with an elevated risk for peri-implantitis $(40-42,44)$. If a cement-retained restoration is used, clinicians should consider placing abutment-restoration margin as coronally as possible to allow more effective removal of excessive cements during the delivery (Figure 2) $(45,46)$. Occlusal scheme on dental implant restoration should be carefully designed, free of any excessive occlusion on centric or excursive movement. Although the availability of literature is limited, a negative effect of occlusion on dental implant was suggested predominantly in animal studies (47-53). Similar to natural dentitions (54), open interproximal contact around a dental implant restoration was also associated with a higher probing depth, plaque index scores, and gingival index scores as well as 1.57 times greater risk of developing peri-implant disease (55). Prior to insertion, abutment and restorative complex should be carefully evaluated for any rough surface texture, which might have been developed during its laboratory fabrication. Rough abutment surface has a potential of harboring 25 times greater amount of dental plaque compared to standard polished surface, which promotes localized accumulation of dental plaque, potentially leading to initiation of periimplant diseases (56). 

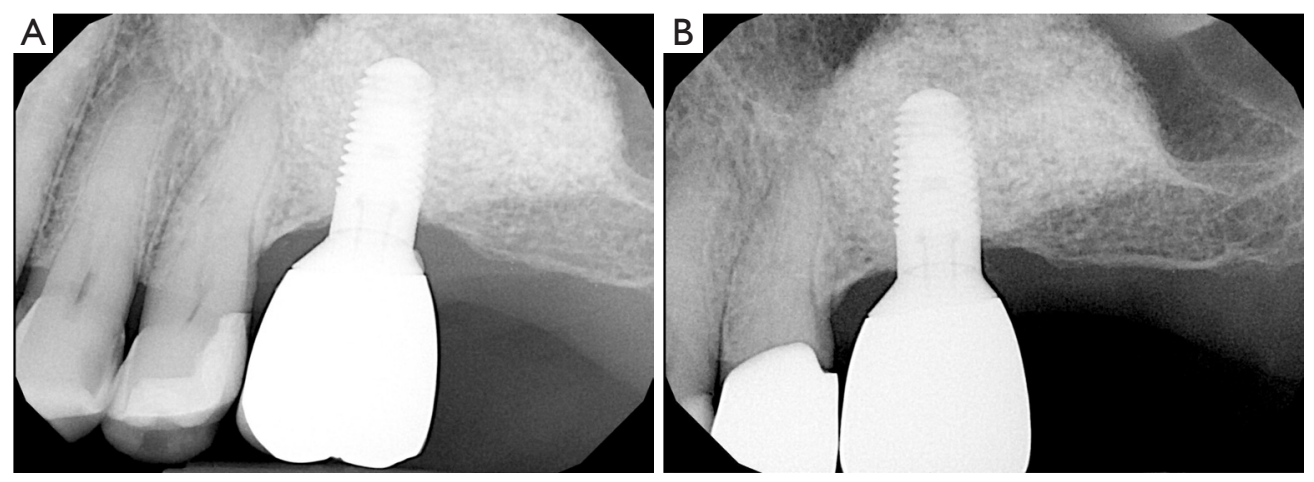

Figure 2 Identification and removal of excessive cement residue around dental implant-restorative complex. (A) Following the insertion of the restoration on the maxillary left first molar implant, excessive cement residue was noted on the distal aspect during the follow-up. (B) The patient received localized sub-peri-implant mucosal debridement, which successfully remove the excessive cement on the distal aspect.

\section{Diabetes mellitus}

Patients with uncontrolled diabetes mellitus were reported to be at a greater risk for developing peri-implant diseases $(7,22,57,58)$. In a recent meta-analysis, diabetic patients were at 1.46 times greater risk for developing peri-implantitis than non-diabetic patients (57). More specifically, patients with hyperglycemia were at 3.39 times greater risk of developing peri-implantitis than normoglycemia (57). This elevated risk of peri-implantitis in patients with hyperglycemia compared to patients with normoglycemia is possibly due to their changes in host immune responses, connective tissue metabolism, and micro and microvasculature around dental implants (59-64). Thus, prior to initiating implant therapy, clinicians should inform patients with diabetes about an elevated risk of developing peri-implantitis. If necessary, a consultation with medical providers should be considered.

\section{Lack of keratinized tissue}

Similar to natural dentitions, implants with lack of keratinized tissue exhibited significantly more inflammation in their peri-implant mucosa compared to those with adequate amount of keratinized tissue $(65,66)$. Having an adequate amount of keratinized tissue may reduce plaque accumulation around the implants and reduce peri-implant mucosal recessions (Figure 3) (67). Furthermore, implants with less than $2 \mathrm{~mm}$ width of keratinized mucosa were at 1.53 and 1.87 times greater risk of developing peri-implant mucositis and peri-implantitis respectively (68). A recent study comparing implants with soft tissue augmentation with those without soft tissue augmentation reported that soft tissue augmentation was significantly associated with reduction in bleeding on probing as well as probing depth. Similarly, significant lower bleeding on probing, mucosal recession, marginal bone loss, and clinical attachment level were noted on implants with thick soft tissue biotype, compared to those with thin biotype (69).

If a prospective implant site is deficient with keratinized tissue, clinicians should consider augmenting the soft tissue to allow an adequate plaque control and to reduce periimplant inflammation, which may minimize the incidence of peri-implant diseases (Figure 4). Proper planning of the flap at implant placement and second stage surgery are utmost importance and might prevent the need for future soft tissue interventions.

\section{Early diagnosis}

Early diagnosis allows clinicians to provide the necessary intervention in a timely manner. Thus, clinicians should continuously monitor the implants during regular maintenance therapy (1). Patients with the aforementioned risk factors and contributing factors should be carefully monitored for any early signs of peri-implant diseases. The risk factors and contributing factors should also be modified or even eliminated to reduce the potential for disease occurrence and progression (6). Shortly after completing restorations on dental implants, baseline clinical and radiographic parameters should be obtained to which those from maintenance therapy can be routinely compared (2). There is limited literature associating a specific range of probing depth with peri-implant health $(2,70)$. The probing depth in implants varies depending on the thickness of the 

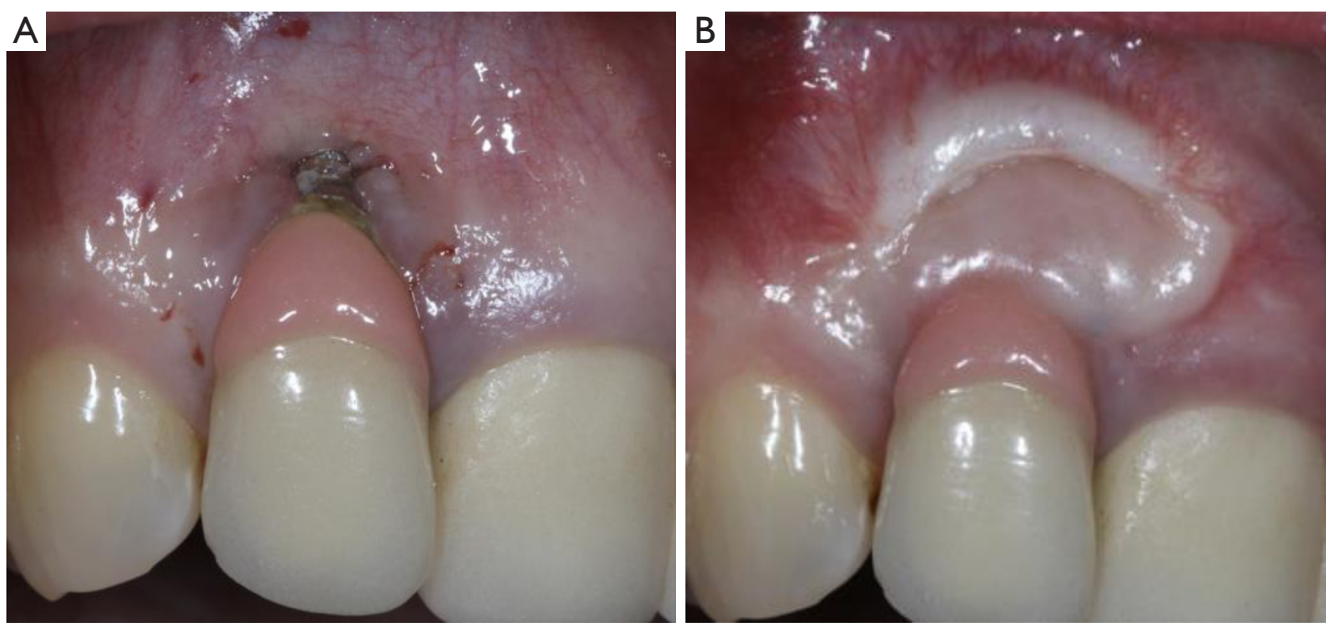

Figure 3 Identification and successful therapeutic resolution of lack of keratinized tissue around dental implant-restorative complex. (A) Implant with lack of keratinized tissue is prone to pronounced plaque accumulation, initiating localized inflammation, potentially eventual peri-implant diseases. The above maxillary right lateral incisor implant was diagnosed as having peri-implantitis, which was associated with complete lack of keratinized tissue, plaque accumulation, deep probing depth of $10 \mathrm{~mm}$, bleeding on probing and suppuration. (B) After augmenting keratinized tissue, at 3-year follow-up, the same implant exhibited complete resolution of inflammation, minimally visible dental plaque, probing depth of $3 \mathrm{~mm}$, no bleeding on probing and no suppuration. Following the soft tissue therapy, the implant has been successfully maintained non-surgically with repeated maintenance and home cares therapy.
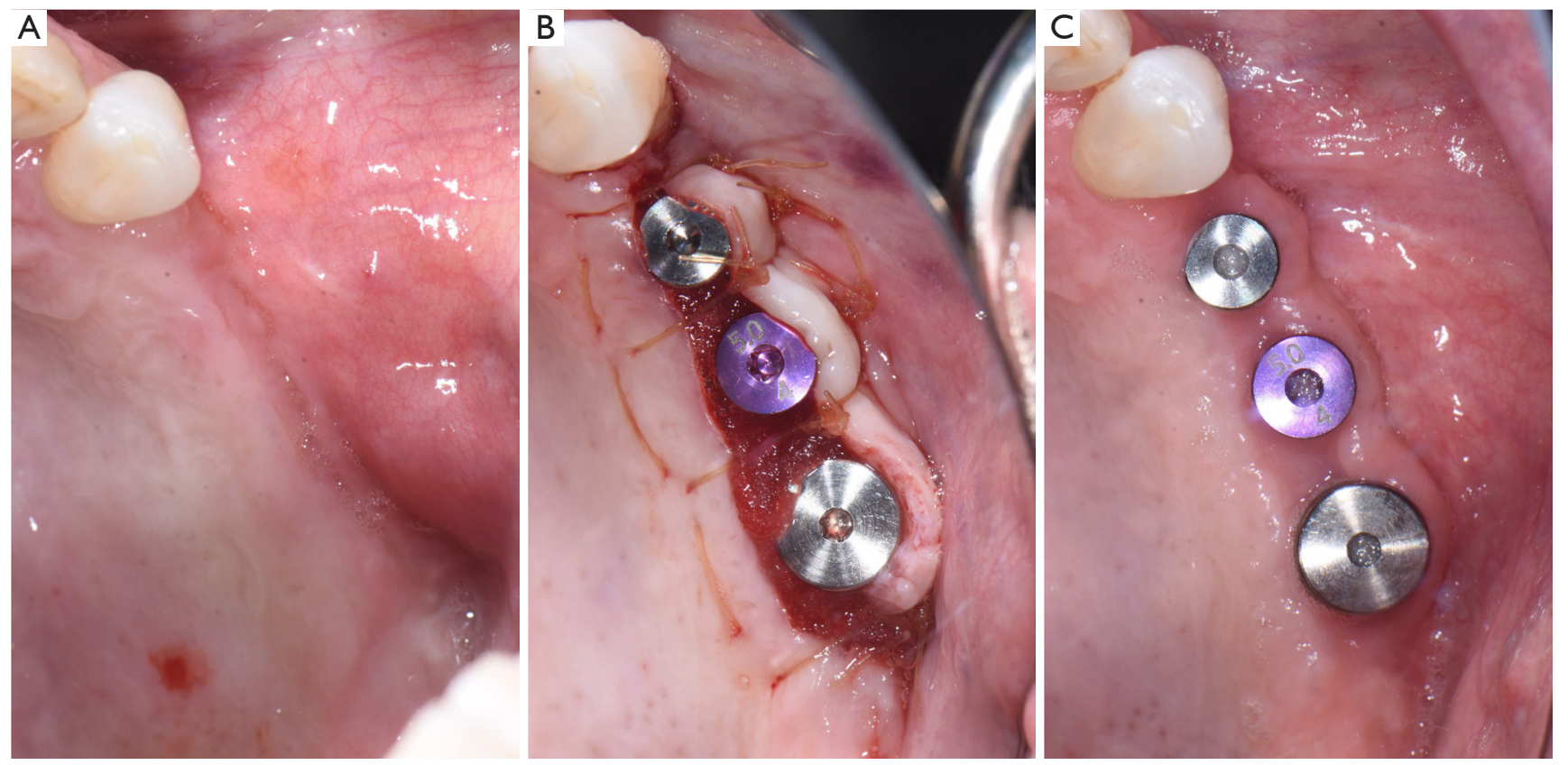

Figure 4 Successful augmentation of keratinized tissue during the uncovering of dental implants. (A) Maxillary left posterior implant sites exhibited a lack of buccal keratinized tissue prior to their uncovering. (B) A palatal crestal incision was performed. The flap containing the palatal keratinized tissue was re-positioned buccal to the implants and their healing abutments. (C) At 6-week follow-up, a significant increase in keratinized tissue was noted buccal to the implants. 
soft tissue at their location, thus providing limited value in diagnosis of peri-implant diseases $(2,70)$. Thus, clinicians should focus more on any change in probing depth compared to the baseline. An increase in probing depth may be related to peri-implant mucosal edema and decrease in probing resistance, possibly suggesting the presence of peri-implant inflammation or disease $(2,7,71)$. Bleeding on probing should be also considered to help distinguish peri-implant health and disease $(2,7,71)$. According to a recent systematic review and meta-analysis, for implants with bleeding on probing, there was $24 \%$ chances to be diagnosed with peri-implantitis (72). Furthermore, in a recent analysis of a total of 334 implants with periimplantitis, approximately $28 \%$ of these implants exhibited suppuration on probing, predominantly on their buccal aspect (73). Periodically, a radiograph should be obtained to assess any presence or progression of alveolar bone loss. A long-cone parallel radiographic projection technique is recommended to assess interproximal crestal bone levels (74). Generally, $1 \mathrm{~mm}$ of marginal bone loss in the first year and an average of $0.2 \mathrm{~mm}$ annually thereafter has been regarded as being acceptable (75). Thus, any bone loss beyond this acceptable change may warrant further evaluation for potential peri-implant disease. If necessary, a cone beam computed tomography may be utilized especially for buccal-lingual visualization of the alveolar bone surrounding dental implants (76). In a recent evaluation of patients who received implant therapy, presence of bleeding on probing, suppuration on probing and presence of radiographic bone loss of greater than $0.5-1$ $\mathrm{mm}$ provided the best diagnostic accuracy in identifying peri-implantitis (77). Other parameters such as mucosal recession, width of remaining keratinized tissue, any sign of inflammation (i.e., erythema, edema), and mobility should also be recorded $(2,7)$. Plaque index may be recorded to continuously assess patient's compliance with suggested home oral care (78).

\section{Non-surgical peri-implant therapy}

Initial treatment of peri-implant disease includes localized non-surgical mechanical debridement in combination with home care therapy. The concept of cause related therapy should be applied, specifically targetting the etiologic factor, dental plaque around dental implants $(16,17)$. Clinicians should educate their patients about the main etiologic factor, dental plaque, and guide them to remove dental plaque effectively at home (16-18). Clinicians should carefully review and update patients' medical and dental history to reveal any potential risk indicators such as smoking habit and diabetic conditions. Clinicians should further evaluate patients for any recurrence or initiation of active periodontal disease. The implant should be carefully examined for any presence of excessive cement residues, excessive centric and lateral excursive occlusal contact, and open interproximal contact. If necessary, the existing restorations should be modified or altered to facilitate patients' plaque control. In a recent randomized controlled trial, modifying the contour of the implant prostheses to improve access for home care therapy significantly improved clinical outcome of the standard mechanical treatment of peri-implant mucositis as measured by changes in bleeding index and probing depth (79). After eliminating and correcting the aforementioned contributing factors, non-surgical mechanical debridement should be initiated. For peri-implant mucositis with inflammation confined in soft-tissue without apparent alveolar bone loss surrounding the fixture, conventional non-surgical mechanical therapy in combination with home care therapy is the standard treatment, resulting in $0.5-1 \mathrm{~mm}$ pocket depth reduction and $15-40 \%$ reduction in bleeding on probing $(74,80-83)$. For peri-implantitis with alveolar bone loss around the fixture, clinicians should assume that implant fixture surface is heavily contaminated and should use conventional automated and hand scaler to ensure effective removal of dental plaque or biofilm around the contaminated implant fixture (Figure 5) (84). Non-surgical mechanical debridement alone usually provides $20-50 \%$ reduction in bleeding on probing and in some cases pocket reduction $(\leq 1 \mathrm{~mm})$ in periimplantitis (74,85-89). Thus, in advanced cases, complete resolution of the disease is unlikely and many need adjunctive treatment to improve the magnitude of improvement (74). For accessible surface, implantoplasty can be performed using a high speed carbide bur with rigorous water cooling to further remove residual dental plaque and their associated debris and to convert a rough to a smoothened surface, allowing more effective plaque removal during maintenance phase by patients and treating clinicians $(56,90,91)$. Various adjunctive therapeutic modalities in addition to non-surgical therapy were reported utilizing systemic antibiotics, locally delivered antimicrobial, laser, photodynamic therapy, and air polishing; however clinicians should carefully utilize these modalities considering a limited availability of evidence in the literature $(74,85,87,88,92-94)$. 

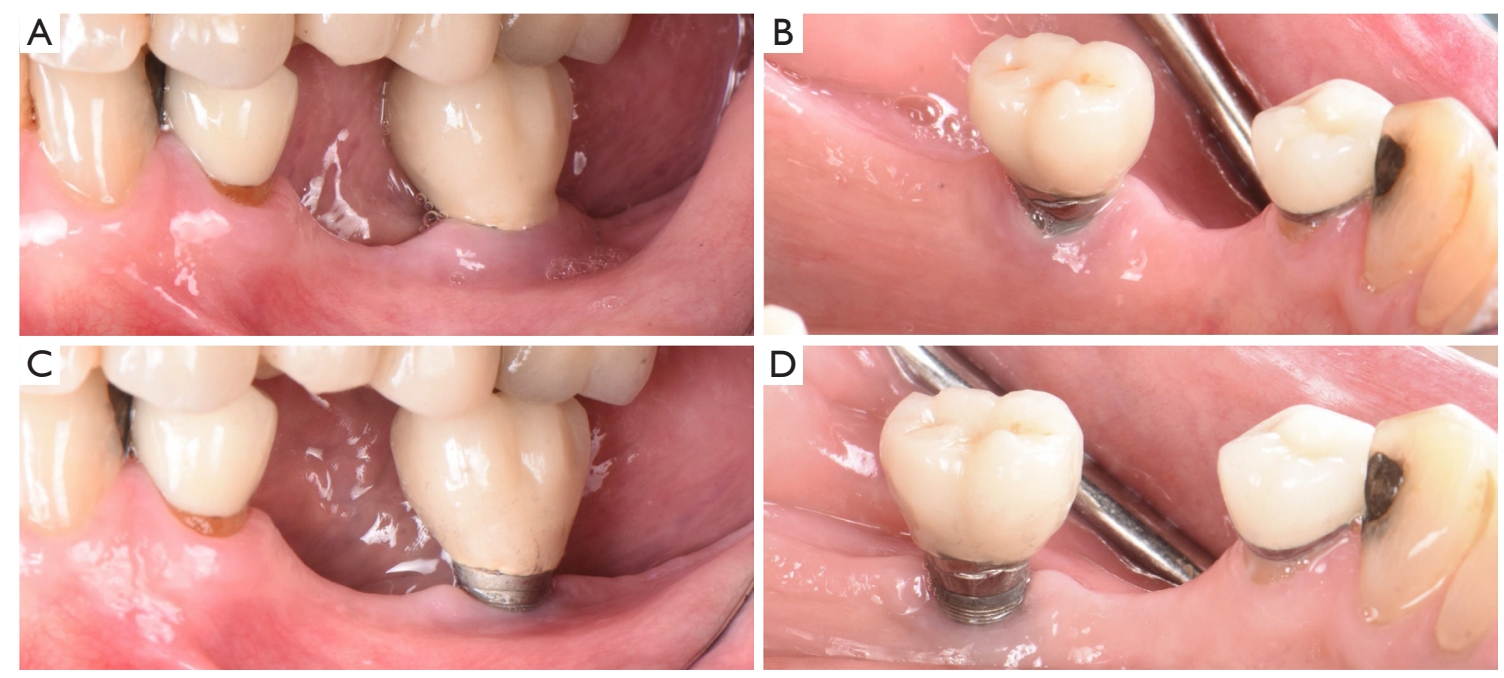

Figure 5 Non-surgical management of peri-implantitis. (A,B) A mandibular left first molar implant with peri-implantitis exhibited 7-8 $\mathrm{mm}$ probing depths, bleeding on probing and bleeding on suppuration. Peri-implant mucosa were edematous and erythematous. (C,D) After non-surgical peri-implant therapy, consisting of home care therapy and professional mechanical debridement, a significant reduction in probing depth to 3-4 $\mathrm{mm}$ with resolution of bleeding and suppuration on probing was noted at re-evaluation. Furthermore, a complete resolution of peri-implant mucosal erythema and edema was noted.

\section{Peri-implant re-evaluation and maintenance therapy}

Following the completing non-surgical peri-implant therapy, peri-implant re-evaluation should be performed in 4-6 weeks to determine the magnitude of improvement. For non-responsive sites especially in advanced peri-implantitis, surgical interventions may be necessary to further eradicate the residual disease (95). The surgical interventions include, but not limited to, traditional open flap debridement with or without resective surgery, contemporary peri-implant guided bone regenerative therapy or combination of both modalities (96-98). Following the successful resolution of peri-implant diseases or even the initial completion of implant therapy (i.e., delivery of implant restoration), patients should receive regular implant maintenance therapy. The maintenance interval should be at least every 5-6 months; however it should be continuously updated or modified based on each patient's risk for peri-implant diseases $(36,38,99)$. During the maintenance therapy, clinicians should continuously monitor their patients for any recurrence or initiation of the disease. As discussed earlier, regular implant maintenance therapy significantly lowers one's risk for peri-implant diseases (35-37). A simplified flow-chart outlining each phase of managing implants with peri-implant disease is presented in Figure 6.

\section{Conclusions}

Peri-implant disease is common biological complication of implant therapy. Throughout all phases of implant therapy (i.e., treatment planning, surgical, restorative, and maintenance phase), clinicians and patients should continuously target its etiologic factor, dental plaque, and other contributing factors to minimize the risk of developing peri-implant disease. Furthermore, during the maintenance therapy, implants should be carefully examined for any early signs suggesting initiation of periimplant disease. If indicated, non-surgical therapy should be initiated in a timely manner, followed by surgical therapy for non-responsive sites.

\section{Acknowledgments}

Funding: None.

\section{Footnote}

Provenance and Peer Review: This article was commissioned by the Guest Editor (Ole T. Jensen) for the series "Current Advances in Treatment of Peri-Implantitis" in Frontiers of Oral and Maxillofacial Medicine. The article has undergone external peer review. 


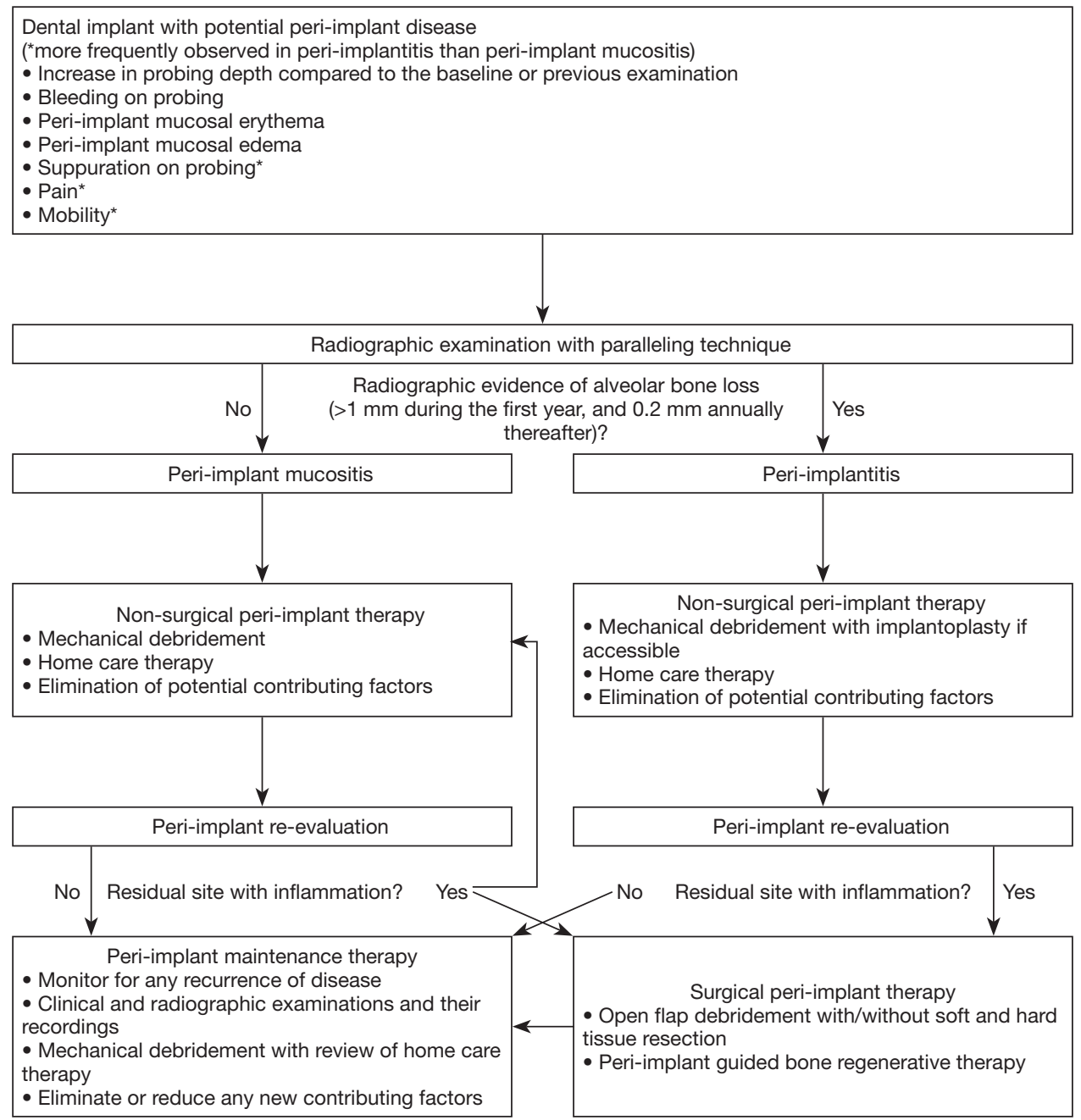

Figure 6 Implants should be carefully examined for any early signs suggesting initiation of peri-implant diseases (i.e., peri-implant mucositis and peri-implantitis). For implants with peri-implant diseases, non-surgical therapy should be initiated in a timely manner. Any sites that are not responsive to non-surgical therapy should be treated surgically. After successful resolution of the disease, patients should be monitored continuously for any recurrence of disease through regular maintenance therapy.

Reporting Checklist: The authors have completed the Narrative Review reporting checklist. Available at https:// fomm.amegroups.com/article/view/10.21037/fomm-21-58/ rc

Conflicts of Interest: All authors have completed the ICMJE uniform disclosure form (available at https://fomm. amegroups.com/article/view/10.21037/fomm-21-58/ coif). The series "Current Advances in Treatment of PeriImplantitis" was commissioned by the editorial office without any funding or sponsorship. The authors have no other conflicts of interest to declare.
Etbical Statement: The authors are accountable for all aspects of the work in ensuring that questions related to the accuracy or integrity of any part of the work are appropriately investigated and resolved.

Open Access Statement: This is an Open Access article distributed in accordance with the Creative Commons AttributionNonCommercial-NoDerivs 4.0 International License (CC BYNC-ND 4.0), which permits the non-commercial replication and distribution of the article with the strict proviso that no changes or edits are made and the original work is properly cited (including links to both the formal publication through the 
relevant DOI and the license). See: https://creativecommons. org/licenses/by-nc-nd/4.0/.

\section{References}

1. Kwon T, Wang CW, Salem DM, et al. Nonsurgical and surgical management of biologic complications around dental implants: peri-implant mucositis and periimplantitis. Quintessence Int 2020;51:810-20.

2. Berglundh T, Armitage G, Araujo MG, et al. Peri-implant diseases and conditions: Consensus report of workgroup 4 of the 2017 World Workshop on the Classification of Periodontal and Peri-Implant Diseases and Conditions. J Periodontol 2018;89 Suppl 1:S313-8.

3. Jepsen S, Berglundh T, Genco R, et al. Primary prevention of peri-implantitis: managing peri-implant mucositis. J Clin Periodontol 2015;42 Suppl 16:S152-7.

4. Hentenaar DFM, De Waal YCM, Vissink A, et al. Biomarker levels in peri-implant crevicular fluid of healthy implants, untreated and non-surgically treated implants with peri-implantitis. J Clin Periodontol 2021;48:590-601.

5. Atieh MA, Alsabeeha NH, Faggion CM Jr, et al. The frequency of peri-implant diseases: a systematic review and meta-analysis. J Periodontol 2013;84:1586-98.

6. Lee CT, Huang YW, Zhu L, et al. Prevalences of periimplantitis and peri-implant mucositis: systematic review and meta-analysis. J Dent 2017;62:1-12.

7. Schwarz F, Derks J, Monje A, et al. Peri-implantitis. J Periodontol 2018;89 Suppl 1:S267-90.

8. Romandini M, Pedrinaci I, Lima C, et al. Prevalence and risk/protective indicators of buccal soft tissue dehiscence around dental implants. J Clin Periodontol 2021;48:455-63.

9. Salvi GE, Cosgarea R, Sculean A. Prevalence and Mechanisms of Peri-implant Diseases. J Dent Res 2017;96:31-7.

10. Green BN, Johnson CD, Adams A. Writing narrative literature reviews for peer-reviewed journals: secrets of the trade. J Chiropr Med 2006;5:101-17.

11. Renvert S, Quirynen M. Risk indicators for periimplantitis. A narrative review. Clin Oral Implants Res 2015;26 Suppl 11:15-44.

12. Heitz-Mayfield LJ, Lang NP. Comparative biology of chronic and aggressive periodontitis vs. peri-implantitis. Periodontol 2000 2010;53:167-81.

13. Lu H, Yan X, Zhu B, et al. The occurrence of periimplant mucositis associated with the shift of submucosal microbiome in patients with a history of periodontitis during the first two years. J Clin Periodontol 2021;48:441-54.

14. Page RC, Offenbacher S, Schroeder HE, et al. Advances in the pathogenesis of periodontitis: summary of developments, clinical implications and future directions. Periodontol 2000 1997;14:216-48.

15. Ferreira SD, Silva GLM, Cortelli JR, et al. Prevalence and risk variables for peri-implant disease in Brazilian subjects. J Clin Periodontol 2006;33:929-35.

16. Kwon T, Levin L. Cause-related therapy: a review and suggested guidelines. Quintessence Int 2014;45:585-91.

17. Kwon T, Salem DM, Levin L. Nonsurgical periodontal therapy based on the principles of cause-related therapy: rationale and case series. Quintessence Int 2019;50:370-6.

18. Kwon T, Wang JCW, Levin L. Home Care is Therapeutic. Should We Use the Term "Home-care Therapy" Instead of "Instructions"? Oral Health Prev Dent 2020;18:397-8.

19. Liang P, Ye S, McComas M, et al. Evidence-based strategies for interdental cleaning: a practical decision tree and review of the literature. Quintessence Int 2021;52:84-95.

20. Carral C, Flores-Guillén J, Figuero E, et al. Peri-implant radiographic bone level and associated factors in Spain. J Clin Periodontol 2021;48:805-15.

21. Levin L, Ofec R, Grossmann Y, et al. Periodontal disease as a risk for dental implant failure over time: a long-term historical cohort study. J Clin Periodontol 2011;38:732-7.

22. Dreyer H, Grischke J, Tiede C, et al. Epidemiology and risk factors of peri-implantitis: A systematic review. J Periodontal Res 2018;53:657-81.

23. Takamoli J, Pascual A, Martinez-Amargant J, et al. Implant failure and associated risk indicators: A retrospective study. Clin Oral Implants Res 2021;32:619-28.

24. Camelo-Castillo AJ, Mira A, Pico A, et al. Subgingival microbiota in health compared to periodontitis and the influence of smoking. Front Microbiol 2015;6:119.

25. Haffajee AD, Socransky SS. Relationship of cigarette smoking to the subgingival microbiota. J Clin Periodontol 2001;28:377-88.

26. Persson L, Bergström J, Ito H, et al. Tobacco smoking and neutrophil activity in patients with periodontal disease. $\mathrm{J}$ Periodontol 2001;72:90-5.

27. Shivanaikar SS, Faizuddin M, Bhat K. Effect of smoking on neutrophil apoptosis in chronic periodontitis: an immunohistochemical study. Indian J Dent Res 2013;24:147.

28. Renvert S, Aghazadeh A, Hallström H, et al. Factors related to peri-implantitis - a retrospective study. Clin Oral 
Implants Res 2014;25:522-9.

29. Ferreira SD, Martins CC, Amaral SA, et al. Periodontitis as a risk factor for peri-implantitis: Systematic review and meta-analysis of observational studies. J Dent 2018;79:1-10.

30. Swierkot K, Lottholz P, Flores-de-Jacoby L, et al. Mucositis, peri-implantitis, implant success, and survival of implants in patients with treated generalized aggressive periodontitis: 3- to 16-year results of a prospective longterm cohort study. J Periodontol 2012;83:1213-25.

31. Guarnieri R, Di Nardo D, Di Giorgio G, et al. Longevity of Teeth and Dental Implants in Patients Treated for Chronic Periodontitis Following Periodontal Maintenance Therapy in a Private Specialist Practice: A Retrospective Study with a 10-Year Follow-up. Int J Periodontics Restorative Dent 2021;41:89-98.

32. Cho-Yan Lee J, Mattheos N, Nixon KC, et al. Residual periodontal pockets are a risk indicator for peri-implantitis in patients treated for periodontitis. Clin Oral Implants Res 2012;23:325-33.

33. Aoki M, Takanashi K, Matsukubo T, et al. Transmission of periodontopathic bacteria from natural teeth to implants. Clin Implant Dent Relat Res 2012;14:406-11.

34. Jansson L, Lundmark A, Modin C, et al. Intra-individual cytokine profile in peri-implantitis and periodontitis: A cross-sectional study. Clin Oral Implants Res 2021;32:559-68.

35. Costa FO, Takenaka-Martinez S, Cota LO, et al. Periimplant disease in subjects with and without preventive maintenance: a 5-year follow-up. J Clin Periodontol 2012;39:173-81.

36. Monje A, Wang HL, Nart J. Association of Preventive Maintenance Therapy Compliance and Peri-Implant Diseases: A Cross-Sectional Study. J Periodontol 2017;88:1030-41.

37. Lin CY, Chen Z, Pan WL, et al. The effect of supportive care in preventing peri-implant diseases and implant loss: A systematic review and meta-analysis. Clin Oral Implants Res 2019;30:714-24.

38. Monje A, Aranda L, Diaz KT, et al. Impact of Maintenance Therapy for the Prevention of Peri-implant Diseases: A Systematic Review and Meta-analysis. J Dent Res 2016;95:372-9.

39. Pons R, Nart J, Valles C, et al. Self-administered proximal implant-supported hygiene measures and the association to peri-implant conditions. J Periodontol 2021;92:389-99.

40. Korsch M, Walther W. Peri-Implantitis Associated with Type of Cement: A Retrospective Analysis of Different
Types of Cement and Their Clinical Correlation to the Peri-Implant Tissue. Clin Implant Dent Relat Res 2015;17 Suppl 2:e434-43.

41. Kotsakis GA, Zhang L, Gaillard P, et al. Investigation of the Association Between Cement Retention and Prevalent Peri-Implant Diseases: A Cross-Sectional Study. J Periodontol 2016;87:212-20.

42. Quaranta A, Lim ZW, Tang J, et al. The Impact of Residual Subgingival Cement on Biological Complications Around Dental Implants: A Systematic Review. Implant Dent 2017;26:465-74.

43. Staubli N, Walter C, Schmidt JC, et al. Excess cement and the risk of peri-implant disease - a systematic review. Clin Oral Implants Res 2017;28:1278-90.

44. Wilson TG Jr, Valderrama P, Burbano M, et al. Foreign bodies associated with peri-implantitis human biopsies. J Periodontol 2015;86:9-15.

45. Linkevicius T, Vindasiute E, Puisys A, et al. The influence of the cementation margin position on the amount of undetected cement. A prospective clinical study. Clin Oral Implants Res 2013;24:71-6.

46. Linkevicius T, Puisys A, Vindasiute E, et al. Does residual cement around implant-supported restorations cause periimplant disease? A retrospective case analysis. Clin Oral Implants Res 2013;24:1179-84.

47. Chambrone L, Chambrone LA, Lima LA. Effects of occlusal overload on peri-implant tissue health: a systematic review of animal-model studies. J Periodontol 2010;81:1367-78.

48. Chang M, Chronopoulos V, Mattheos N. Impact of excessive occlusal load on successfully-osseointegrated dental implants: a literature review. J Investig Clin Dent 2013;4:142-50.

49. Isidor F. Histological evaluation of peri-implant bone at implants subjected to occlusal overload or plaque accumulation. Clin Oral Implants Res 1997;8:1-9.

50. Kim Y, Oh TJ, Misch CE, et al. Occlusal considerations in implant therapy: clinical guidelines with biomechanical rationale. Clin Oral Implants Res 2005;16:26-35.

51. Merin RL. Repair of peri-implant bone loss after occlusal adjustment: a case report. J Am Dent Assoc 2014;145:1058-62.

52. Naert I, Duyck J, Vandamme K. Occlusal overload and bone/implant loss. Clin Oral Implants Res 2012;23 Suppl 6:95-107.

53. Passanezi E, Sant'Ana AC, Damante CA. Occlusal trauma and mucositis or peri-implantitis? J Am Dent Assoc 2017;148:106-12. 
54. Koral SM, Howell TH, Jeffcoat MK. Alveolar bone loss due to open interproximal contacts in periodontal disease. J Periodontol 1981;52:447-50.

55. Latimer JM, Gharpure AS, Kahng HJ, et al. Interproximal open contacts between implant restorations and adjacent natural teeth as a risk-indicator for peri-implant disease-A cross-sectional study. Clin Oral Implants Res 2021;32:598-607.

56. Quirynen M, van der Mei HC, Bollen CM, et al. An in vivo study of the influence of the surface roughness of implants on the microbiology of supra- and subgingival plaque. J Dent Res 1993;72:1304-9.

57. Monje A, Catena A, Borgnakke WS. Association between diabetes mellitus/hyperglycaemia and peri-implant diseases: Systematic review and meta-analysis. J Clin Periodontol 2017;44:636-48.

58. French D, Ofec R, Levin L. Long term clinical performance of 10871 dental implants with up to 22 years of follow-up: A cohort study in 4247 patients. Clin Implant Dent Relat Res 2021;23:289-97.

59. Mealey BL, Oates TW; American Academy of Periodontology. Diabetes mellitus and periodontal diseases. J Periodontol 2006;77:1289-303.

60. Lamster IB, Pagan M. Periodontal disease and the metabolic syndrome. Int Dent J 2017;67:67-77.

61. Lamster IB, Cheng B, Burkett S, et al. Periodontal findings in individuals with newly identified pre-diabetes or diabetes mellitus. J Clin Periodontol 2014;41:1055-60.

62. Lalla E, Lamster IB, Stern DM, et al. Receptor for advanced glycation end products, inflammation, and accelerated periodontal disease in diabetes: mechanisms and insights into therapeutic modalities. Ann Periodontol 2001;6:113-8.

63. Lalla E, Lamster IB, Drury S, et al. Hyperglycemia, glycoxidation and receptor for advanced glycation endproducts: potential mechanisms underlying diabetic complications, including diabetes-associated periodontitis. Periodontol 2000 2000;23:50-62.

64. Schmidt AM, Weidman E, Lalla E, et al. Advanced glycation endproducts (AGEs) induce oxidant stress in the gingiva: a potential mechanism underlying accelerated periodontal disease associated with diabetes. J Periodontal Res 1996;31:508-15.

65. Monje A, Blasi G. Significance of keratinized mucosa/ gingiva on peri-implant and adjacent periodontal conditions in erratic maintenance compliers. J Periodontol 2019;90:445-53.
66. Schrott AR, Jimenez M, Hwang JW, et al. Five-year evaluation of the influence of keratinized mucosa on periimplant soft-tissue health and stability around implants supporting full-arch mandibular fixed prostheses. Clin Oral Implants Res 2009;20:1170-7.

67. Chackartchi T, Romanos GE, Sculean A. Soft tissuerelated complications and management around dental implants. Periodontol 2000 2019;81:124-38.

68. Gharpure AS, Latimer JM, Aljofi FE, et al. Role of thin gingival phenotype and inadequate keratinized mucosa width $(<2 \mathrm{~mm})$ as risk indicators for peri-implantitis and peri-implant mucositis. J Periodontol 2021. [Epub ahead of print]. doi: 10.1002/JPER.20-0792.

69. Isler SC, Uraz A, Kaymaz O, et al. An Evaluation of the Relationship Between Peri-implant Soft Tissue Biotype and the Severity of Peri-implantitis: A Cross-Sectional Study. Int J Oral Maxillofac Implants 2019;34:187-196.

70. Coli P, Sennerby L. Is Peri-Implant Probing Causing Over-Diagnosis and Over-Treatment of Dental Implants? J Clin Med 2019;8:1123.

71. Renvert S, Persson GR, Pirih FQ, et al. Peri-implant health, peri-implant mucositis, and peri-implantitis: Case definitions and diagnostic considerations. J Periodontol 2018;89 Suppl 1:S304-12.

72. Hashim D, Cionca N, Combescure C, et al. The diagnosis of peri-implantitis: A systematic review on the predictive value of bleeding on probing. Clin Oral Implants Res 2018;29 Suppl 16:276-93.

73. Monje A, Vera M, Muñoz-Sanz A, et al. Suppuration as diagnostic criterium of peri-implantitis. J Periodontol 2021;92:216-24.

74. Renvert S, Hirooka H, Polyzois I, et al. Diagnosis and non-surgical treatment of peri-implant diseases and maintenance care of patients with dental implants Consensus report of working group 3. Int Dent J 2019;69 Suppl 2:12-7.

75. Albrektsson T, Zarb G, Worthington P, et al. The longterm efficacy of currently used dental implants: a review and proposed criteria of success. Int J Oral Maxillofac Implants 1986;1:11-25.

76. Dave M, Davies J, Wilson R, et al. A comparison of cone beam computed tomography and conventional periapical radiography at detecting peri-implant bone defects. Clin Oral Implants Res 2013;24:671-8.

77. Romandini M, Berglundh J, Derks J, et al. Diagnosis of peri-implantitis in the absence of baseline data: A diagnostic accuracy study. Clin Oral Implants Res 
2021;32:297-313.

78. O'Leary TJ, Drake RB, Naylor JE. The plaque control record. J Periodontol 1972;43:38.

79. de Tapia B, Mozas C, Valles C, et al. Adjunctive effect of modifying the implant-supported prosthesis in the treatment of peri-implant mucositis. J Clin Periodontol 2019;46:1050-60.

80. Aimetti M, Mariani GM, Ferrarotti F, et al. Adjunctive efficacy of diode laser in the treatment of peri-implant mucositis with mechanical therapy: A randomized clinical trial. Clin Oral Implants Res 2019;30:429-38.

81. Serino G, Wada M. Non-surgical mechanical treatment of peri-implant mucositis: the effect of sub-mucosal mechanical instrumentation following supra-mucosal plaque removal. A 7-month prospective single cohort study. Eur J Oral Implantol 2018;11:455-66.

82. Riben-Grundstrom C, Norderyd O, André U, et al. Treatment of peri-implant mucositis using a glycine powder air-polishing or ultrasonic device: a randomized clinical trial. J Clin Periodontol 2015;42:462-9.

83. Gomes SC, Corvello P, Romagna R, et al. How do periimplant mucositis and gingivitis respond to supragingival biofilm control - an intra-individual longitudinal cohort study. Eur J Oral Implantol 2015;8:65-73.

84. Fox SC, Moriarty JD, Kusy RP. The effects of scaling a titanium implant surface with metal and plastic instruments: an in vitro study. J Periodontol 1990;61:485-90.

85. Hentenaar DFM, De Waal YCM, Stewart RE, et al. Erythritol airpolishing in the non-surgical treatment of peri-implantitis: A randomized controlled trial. Clin Oral Implants Res 2021;32:840-52.

86. Wagner TP, Pires PR, Rios FS, et al. Surgical and nonsurgical debridement for the treatment of peri-implantitis: a two-center 12-month randomized trial. Clin Oral Investig 2021. [Epub ahead of print]. doi: 10.1007/s00784021-03874-z.

87. Machtei EE, Romanos G, Kang P, et al. Repeated delivery of chlorhexidine chips for the treatment of peri-implantitis: A multicenter, randomized, comparative clinical trial. J Periodontol 2021;92:11-20.

88. Machtei EE, Frankenthal S, Levi G, et al. Treatment of peri-implantitis using multiple applications of chlorhexidine chips: a double-blind, randomized multicentre clinical trial. J Clin Periodontol 2012;39:1198-205.

89. Arısan V, Karabuda ZC, Arıcı SV, et al. A randomized clinical trial of an adjunct diode laser application for the nonsurgical treatment of peri-implantitis. Photomed Laser Surg 2015;33:547-54.

90. Sivolella S, Brunello G, Michelon F, et al. Implantoplasty: Carbide burs vs diamond sonic tips. An in vitro study. Clin Oral Implants Res 2021;32:324-36.

91. El Chaar E, Almogahwi M, Abdalkader K, et al. Decontamination of the Infected Implant Surface: A Scanning Electron Microscope Study. Int J Periodontics Restorative Dent 2020;40:395-401.

92. Lin GH, Suárez López Del Amo F, Wang HL. Laser therapy for treatment of peri-implant mucositis and periimplantitis: An American Academy of Periodontology best evidence review. J Periodontol 2018;89:766-82.

93. Chambrone L, Wang HL, Romanos GE. Antimicrobial photodynamic therapy for the treatment of periodontitis and peri-implantitis: An American Academy of Periodontology best evidence review. J Periodontol 2018;89:783-803.

94. Shibli JA, Ferrari DS, Siroma RS, et al. Microbiological and clinical effects of adjunctive systemic metronidazole and amoxicillin in the non-surgical treatment of periimplantitis: 1 year follow-up. Braz Oral Res 2019;33:e080.

95. Wang CW, Renvert S, Wang HL. Nonsurgical Treatment of Periimplantitis. Implant Dent 2019;28:155-60.

96. Roccuzzo A, Stähli A, Monje A, et al. Peri-Implantitis: A Clinical Update on Prevalence and Surgical Treatment Outcomes. J Clin Med 2021;10:1107.

97. Khoury F, Keeve PL, Ramanauskaite A, et al. Surgical treatment of peri-implantitis - Consensus report of working group 4. Int Dent J 2019;69 Suppl 2:18-22 .

98. Chan HL, Lin GH, Suarez F, et al. Surgical management of peri-implantitis: a systematic review and meta-analysis of treatment outcomes. J Periodontol 2014;85:1027-41.

99. Surveillance report 2018 - Dental checks: intervals between oral health reviews (2004) NICE guideline CG19. London: National Institute for Health and Care Excellence (UK), 2018. Available online: http://www.ncbi. nlm.nih.gov/books/NBK551810/

doi: 10.21037/fomm-21-58

Cite this article as: Kwon T, Yen HH, Levin L. Peri-implant disease: early diagnosis and non-surgical treatment-a narrative literature review. Front Oral Maxillofac Med 2022;4:38. 